\title{
Photo-resist Removal using Highly Concentrated Ozone Gas - Removal Characteristics of Various Resists-
}

\author{
Toshinori Miura, Mitsuru Kekura, Hideo Horibe*, Masashi Yamamoto* \\ Core Technology Research \& Development Center, Meidensha Corporation \\ 515 Kaminakamizo, Higashimakado, Numazu-Shi, Shizuoka 410-8588 Japan \\ *Department of Material Design Engineering, Graduate School of Engineering, \\ Kanazawa Institute of Technology \\ 3-1 Yatsukaho, Hakusan, Ishikawa, 924-0838 Japan
}

\begin{abstract}
New processing technologies are demanded which produce hyperfine structures for electronic devices and which do not exacerbate environmental problems. We specifically examined photoresist removal technology for this study. Ozone gas of nearly $100 \%$ concentration was applied to various photoresists and ion-implanted-photoresists. Results showed that reactivity with ozone gas differs between a novolac resist, which has a benzene ring structure on a main chain, a $\mathrm{KrF}$ resist with this structure on a side chain, and an $\mathrm{ArF}$ resist which has no such structure. The activation energy of the $\mathrm{KrF}$ resist indicates a value close to that of the novolac resist; the value for the ArF resist was larger than these. Irrespective of the ionic species, the ion-implanted-photoresist of amount $1 \mathrm{e} 16 \mathrm{~cm}^{-2}$ of the dose can be removed with $0.7 \mu \mathrm{m} / \mathrm{min}$ or less in the ashing of $400^{\circ} \mathrm{C}$ in processing temperature. Additionally, results showed that the removal speed slows in order of B, As, and P.
\end{abstract}

Keywords: ozone gas, ashing, resist removal, ion implanted resist

\section{Introduction}

Photoresist removal processes are used tens of times during photolithography for semiconductor device fabrication. Therefore, the photoresist removal method has variously changed by each process. A method of limiting damage to the lower layer is required. Moreover, plasma damage, by charged particles cannot be disregarded when making the fine circuit pattern.

Some methods use chemical washing and/or ozone processing as a plasma-less process. However, the environmental impact of the former poses a problem; slow removal is a problem of the latter.

Conventionally, only ozone gas concentrated to the $10 \mathrm{vol} \%$ level can be used in ozone processing. However, recently, a device that can supply highly concentrated ozone gas of nearly $100 \%$ purity has been developed.[1] It enables plasma-less resist removal with practical removal speeds. For this study, highly concentrated ozone gas of nearly $100 \%$ was applied for some photoresists. The differences of reactivity were examined. Moreover, it was applied for ion implanted photoresists, which require additive chemical washing for removal; then the removal performance was evaluated.

\section{Experiment}

2.1 Ashing of various photoresists

2.1.1 Sample preparation and evaluation method

Photoresists were spin-coated onto 4-inch silicon wafers using a spin coater (1H-D7; Mikasa Co. Ltd.). Photoresists used in this experiment were OFPR-800 (DNQ/Novolac positive-tone photoresist, Fig. 1(a)), TDUR-P509PM (for $\mathrm{KrF}$ 
excimer laser - hereinafter KrF resist, Fig. 1(b)), and TARF-P6071PM (for ArF excimer laser hereinafter ArF resist, Figs. 1(c) and 1(d)) All were produced by Tokyo Ohka Kogyo Co. Ltd. Furthermore, after coating, these had been baked on a hot plate for one minute at $120^{\circ} \mathrm{C}$ (dataplate model \#722 A-1; Iuchi). Film thicknesses were, respectively, $1.2 \mu \mathrm{m}, 0.65 \mu \mathrm{m}$, and $0.4 \mu \mathrm{m}$.

Here, ozonolysis forms ozonide by addition with a double bond uniting the carbon atoms: the reaction includes ozone and the organic molecule.[2] The reactivity was inferred to be different in the novolac resist with double bonds on a main chain as a part of the benzene ring structure, the $\mathrm{KrF}$ resist with benzene ring structure on side chain, and the ArF resist without this structure. In addition, the ArF resist generally has an alicycle group resembling that depicted in Fig. 1(d) to give the plasma tolerance because it has no benzene ring structure stabilized by pi-electron resonance. $[3,4]$

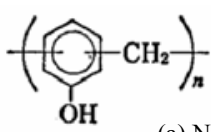

(a) Novolac resin

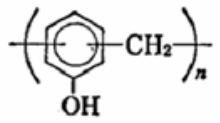

(a) DNQ:Diazonaphthoquinone

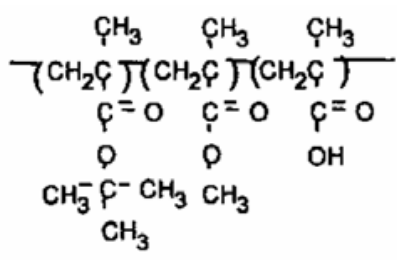

(c) ArF resist base polymer / acrylic polymer

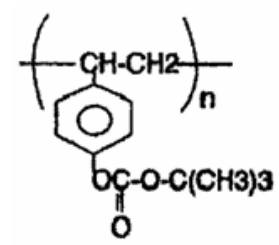

(b) $\mathrm{KrF}$ resist base polymer / PVP:polyvinylphenol (PHS: polyhydroxystyrene)

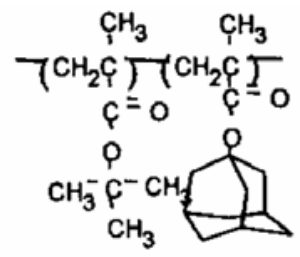

(d) Acrylic polymer containing alicyclic group
Fig. 1 Molecular structures of various photoresists

The photoresist removal speed (ashing rate) was calculated from the processing time: the difference in film thickness before and after ozone processing. The film thickness was measured as the depth of a scribing mark on the photoresist using a stylus profiler (Dektak6M; Veeco Instruments).

\subsubsection{Experimental apparatus}

A schematic view of experimental chamber is presented in Fig. 2. The ozone gas is sprayed onto the sample arranged as opposite to the shower head and it was heated from the bottom side of the susceptor using an infrared lamp. This process was done in a vacuum chamber because the highly concentrated ozone gas under atmospheric pressure might explode through a chain decomposition reaction. [5] In this experiment, phenomena were examined around pressure of $1000 \mathrm{~Pa}$ because the ozone gas that is greater than $50 \mathrm{vol} \%$ in the concentration with pressure 10 Torr $(1333 \mathrm{~Pa})$ or less does not explode by ignition. [6]

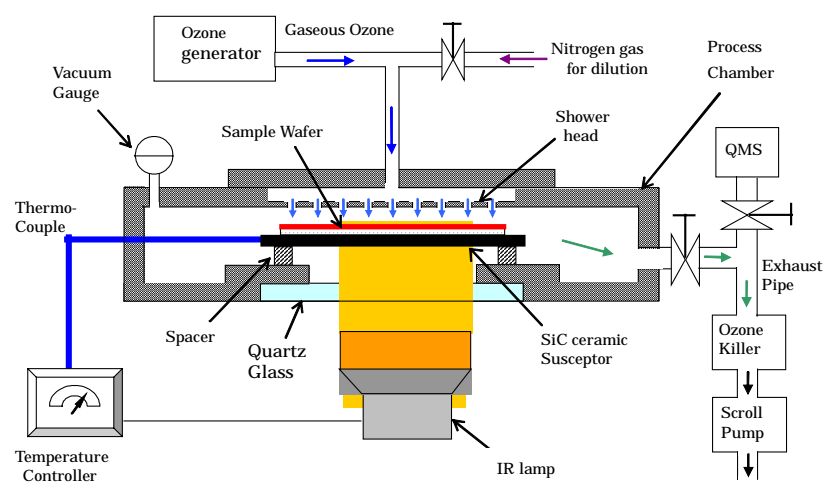

Fig. 2 Schematic view of experimental chamber

The processing was done as follows. First, the Si wafer with the photoresist was set up on the susceptor at room temperature in atmosphere. Next, an infrared lamp was turned on after the pressure of the inner chamber became a few Pascals or less. Furthermore, the susceptor temperature rose about $50^{\circ} \mathrm{C} / \mathrm{min}$. Consequently, after it had reached the desired temperature, ozone gas was introduced. The gas was stopped after a prescribed time. The susceptor temperature fell naturally under vacuum up to $100^{\circ} \mathrm{C}$ to take out the wafer. In addition, the upper lid was removed after $\mathrm{N}_{2}$ gas was introduced. It reached atmospheric pressure; then the sample was taken out.

This process was accomplished under a vacuum environment. Therefore, the number of ozone molecules necessary for being reactive might become insufficient. Then, pressure was changed to 200-3000 Pa, and the result of evaluating the ashing rate is depicted in Fig. 3. Experiments were performed in conditions of flow rate $200 \mathrm{sccm}$ and process temperature of $300^{\circ} \mathrm{C}$. The ashing rate within this experimental condition increased with pressure. No irregular reaction was seen at the highest pressure of $3000 \mathrm{~Pa}$. A steady removal reaction proceeded. 


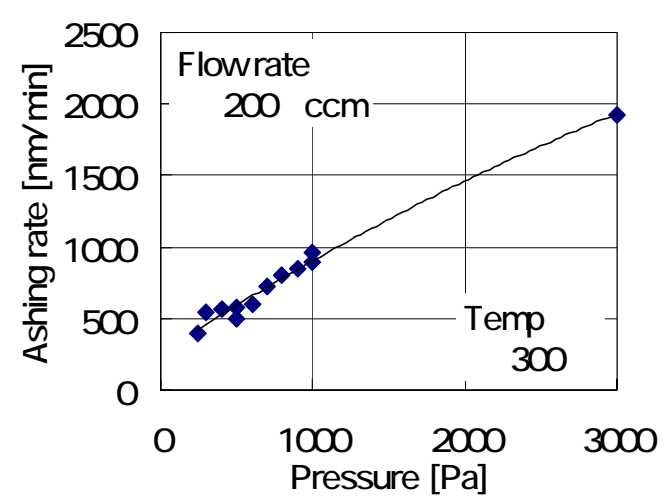

Fig. 3 Ashing rate depends on processing pressure.

\section{Results and Discussion}

Temperature-dependence of the ashing rate in photoresists of three kinds are portrayed in Fig. 4. The Arrhenius plot is presented in Fig. 5. The pressure condition was set to $1000 \mathrm{~Pa}$ because the amount of the resist removal might be evaluated even at the process temperature of $150^{\circ} \mathrm{C}$; the ashing rate was evaluated even in the ArF resist with thinner film thickness and rising temperature.

As a result, OFPR (novolac) was removed faster at $170^{\circ} \mathrm{C}$ or less than any other photoresist. It continued with TDUR (KrF resist) and TARF (ArF resist) as presented in Fig. 4. This is thought to occur because the addition reaction of ozone to the carbon double bond has taken place. This tendency was reversed at $180^{\circ} \mathrm{C}$ and higher temperatures. Therefore, it is thought that the other reactions than the reaction with the ozone molecule are increasing at $180^{\circ} \mathrm{C}$ or more.

In the Arrhenius plot shown in Fig. 5, the inclination has changed at about $180^{\circ} \mathrm{C}$ in TARF and about $200^{\circ} \mathrm{C}$ in OFPR and TDUR. The activation energy $(E a)$ for each temperature, as calculated from these inclinations, is shown in Table 1. The Ea of OFPR and TDUR were similar values; their values were smaller than that of TARF. Therefore, the ashing reaction, is thought to progress by a similar mechanism for OFPR and TDUR.

On the other hand, $E a$ at a high temperature is less than that at the low temperature, which shows that only a little thermal energy is sufficient to react. In general, ashing by ozone gas requires temperatures of about $250^{\circ} \mathrm{C}$ or more. The ashing reaction is said to proceed by the oxygen radical generated by thermal decomposition of ozone.[7-9] Therefore, the changing of Ea here was thought to correspond to the increasing of oxygen radical.

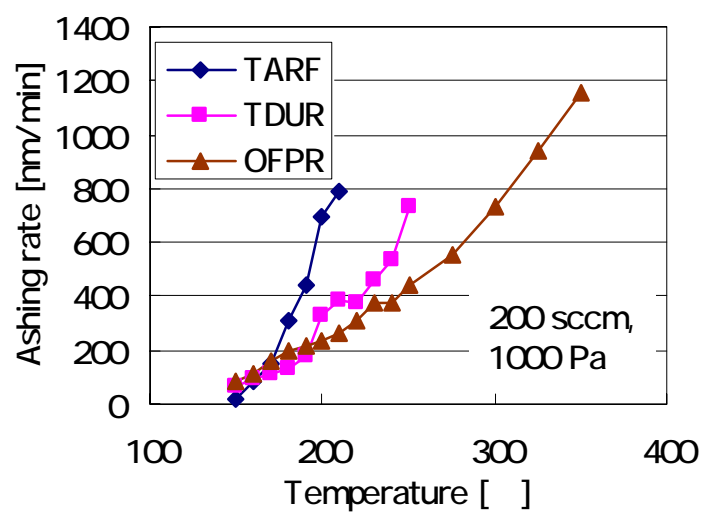

Fig. 4 Relationship between Ashing rate and Temperature.

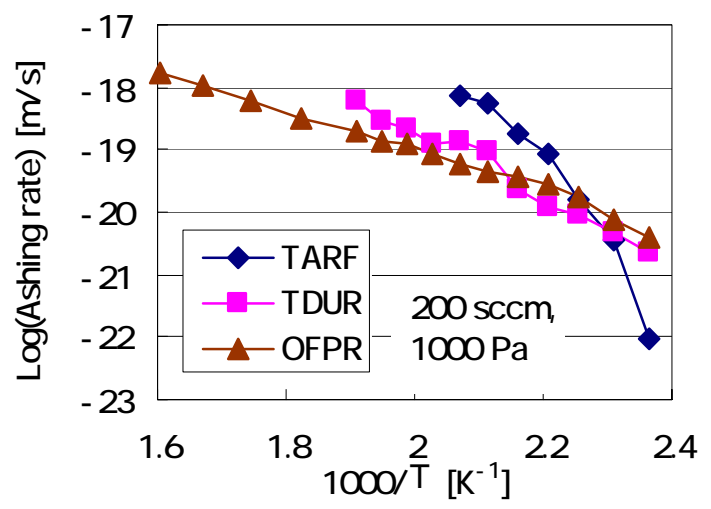

Fig. 5 Arrhenius plot

Table 1 Activation energies (Ea) of OFPR, TDUR and TARF resists

\begin{tabular}{|c|c|c|}
\hline & range $\left[{ }^{\circ} \mathrm{C}\right]$ & $\mathrm{Ea}[\mathrm{eV}]$ \\
\hline $\begin{array}{c}\text { OFPR } \\
\text { (novolac) }\end{array}$ & $150-190$ & 0.43 \\
\cline { 2 - 3 } & $200-350$ & 0.27 \\
\hline TDUR & $150-190$ & 0.41 \\
\cline { 2 - 3 }$($ for KrF) & $200-240$ & 0.25 \\
\hline TARF $\begin{array}{c}\text { TAR } \\
\text { (for ArF) }\end{array}$ & $180-200$ & 0.74 \\
\cline { 2 - 3 } & $150-170$ & 1.80 \\
\hline
\end{tabular}

\subsection{Ion-implanted photoresist}

In the previous section, it was shown that a temperature increase is necessary to obtain high removal ability during application of highly concentrated ozone gas to various photoresists.

This processing was applied to an ion implanted photoresist, which is difficult to remove using conventional methods. The removal ability was examined.

A high-dose ion-implanted photoresist produces many particles through high-temperature processing. This phenomenon is called popping. The photoresist surface is stiffened when the ion is 
implanted. Therefore, when the temperature rises, the surface layer explodes by the pressure increase related to the escaped gas from the lower photoresist. This surface layer is called a carbonized layer or crust (Fig. 6) [10].

However, no reports describe examination of the changes of this phenomenon according to different ion species or the dose amount. The removal of various ion-implanted photoresists using highly concentrated ozone gas was evaluated; popping was examined.

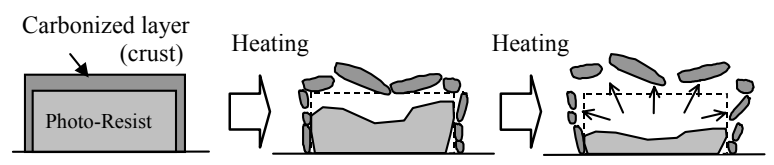

Fig. 6 Popping phenomenon

\subsection{Sample preparation and evaluation method}

As ion species, Boron (B) and Phosphorus (P) and Arsenic (As) were implanted onto spin-coated DNQ/Novolac .photoresist $\quad(0.95-\mu \mathrm{m}$-thick, AZ6112; AZ Electronic Materials). Five dose amounts were used: 5e12, 5e13, 5e14, 5e15, and $1 \mathrm{e} 16 \mathrm{~cm}^{-2}$. That is, 15 samples were prepared. The depth profile of the scribing mark formed on the photoresist was measured as the total film thickness including crust using a stylus profiler (Dektak 6M; Veeco Instruments). The layer structure was evaluated using a spectroscopic ellipsometer (M-2000D; J. A. Woollam Co., Inc.). Here, an optical constant of the crust layer was assumed to be continuously changeable from the lower layer side to the upper layer side in the evaluation of the layer structure by spectroscopic ellipsometer.

\subsection{Structure of ion implanted photoresists}

Figure 7 portrays the ion-implanted photoresist thickness and the crust layer thickness.

The figure shows that the film thickness displays a tendency to thin as the dose amount increases. The polymer of the photoresist was thought to be cross-linked and to have been shrunk by ion implantation. A crust layer is seen at more than $5 \mathrm{e} 14 \mathrm{~cm}^{-2}$ in the As-implanted-sample. It is apparent in more than $5 \mathrm{e} 15 \mathrm{~cm}^{-2}$ in the other samples. It was not possible to measure it when the crust layer was defined as less than these dose amounts. Therefore, it was measured as a film without the crust layer.

In addition, the implanted sample of $\mathrm{P} / 5 \mathrm{e} 15$ $\mathrm{cm}^{-2}$, which has a crust layer, was cut. Then the cross-section of the sample was observed using a scanning electron microscope (SEM). Figure 8 portrays the SEM image of this sample. The surface and the lower layer are distinct. The surface layer was thought to have stiffened. Therefore, surface layer deformation was very slight and the lower layer collapsed, as shown at the photograph edge.

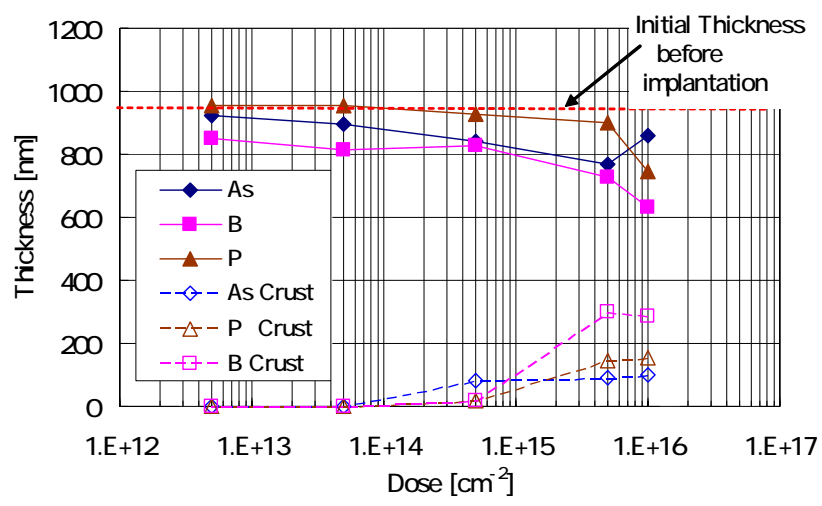

Fig. 7 Film thickness of ion implanted photoresists

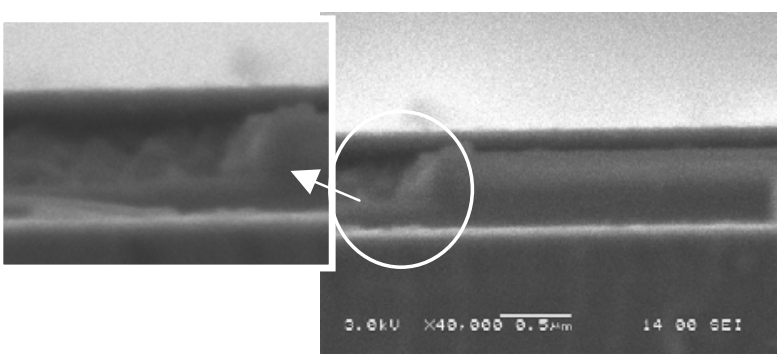

Fig. 8 SEM image of a cross-section of the ion implanted photoresist $\left(\mathrm{P} / 5 \mathrm{e} 15 \mathrm{~cm}^{-2}\right)$.

\subsection{Ashing of ion-implanted photoresists}

As presented in Fig. 2, we used a chamber with a shower head and an upper lid. Here, these have been changed to transparent fused silica to observe the change of photoresist. The sample is the ion-implanted photoresist described above was cut to about $1 \mathrm{~cm} \times 1 \mathrm{~cm}$. The ion-implanted photoresist removal time was measured visually.

The relationship between the process temperature and the photoresist removal time is shown in Fig. 9. These samples were implanted respectively at $1 \mathrm{e} 16 \mathrm{~cm}^{-2}$ dose for each ion species. The removal time was shortened by the temperature rise. Those for each ion species were long in order of $\mathrm{B}<\mathrm{As}<\mathrm{P}$. It was removed within $2 \mathrm{~min}: 0.7 \mu \mathrm{m} / \mathrm{min}$ at $400^{\circ} \mathrm{C}$.

Next, the removal time when processing it at the temperature upper limit $400^{\circ} \mathrm{C}$ of the apparatus 
was evaluated for the sample of each ionic species and of the amount of dose.

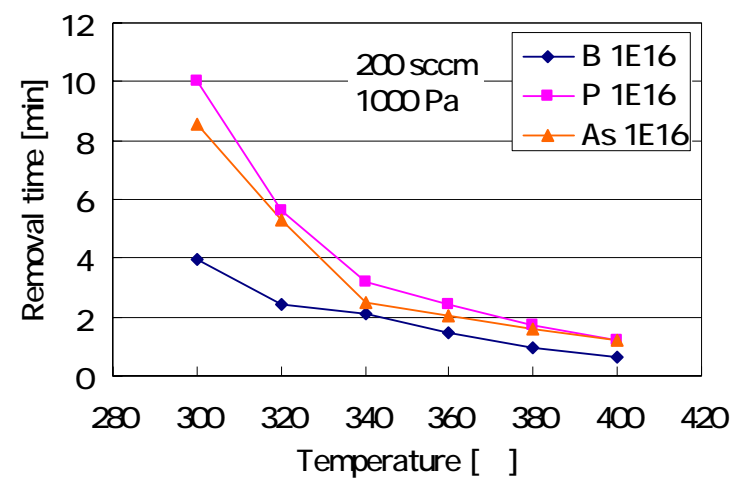

Fig. 9 Relationship between process temperature and removal time of ion implanted photoresists (B,P,As:1e16)

Figure 10 portrays the result:for the unimplanted sample, shown simultaneously as 'non-dope'. The removal time in $5 \mathrm{e} 12 \mathrm{~cm}^{-2}$ of the dose for each ion species was almost equal to an unimplanted one.

Furthermore, although the removal time and roundly disappears in the implanted sample of $\mathrm{P}$, which has more than $5 \mathrm{e} 15 \mathrm{~cm}^{-2}$ or of As, which has more than $5 \mathrm{e} 14 \mathrm{~cm}^{-2}$. Results show that popping occurred.

These and Fig. 7 show that occurrence of a tear of the surface, including the crack in the B sample, corresponds to the sample of about $100 \mathrm{~nm}$ or more in crust layer thickness. Moreover, the crust layer thickness of the B sample in $5 \mathrm{e} 15 \mathrm{~cm}^{-2}$ or more is more than two times that of the other. Therefore, it is thought that the B sample crust layer stiffness is lower than others because the density of implanted ion in the layer is lower and the generation of heat when the ion is implanted does not concentrate in the layer. Additionally, the crust layer leaves plasticity because the sign of rupture and flake of the crust layer is not seen on the B sample in Fig. 11.

Here, the correlation between the amount of dose and the removal time were changed in the high dose sample in Fig. 10 for the following reasons because of the situation of the occurrence of popping.

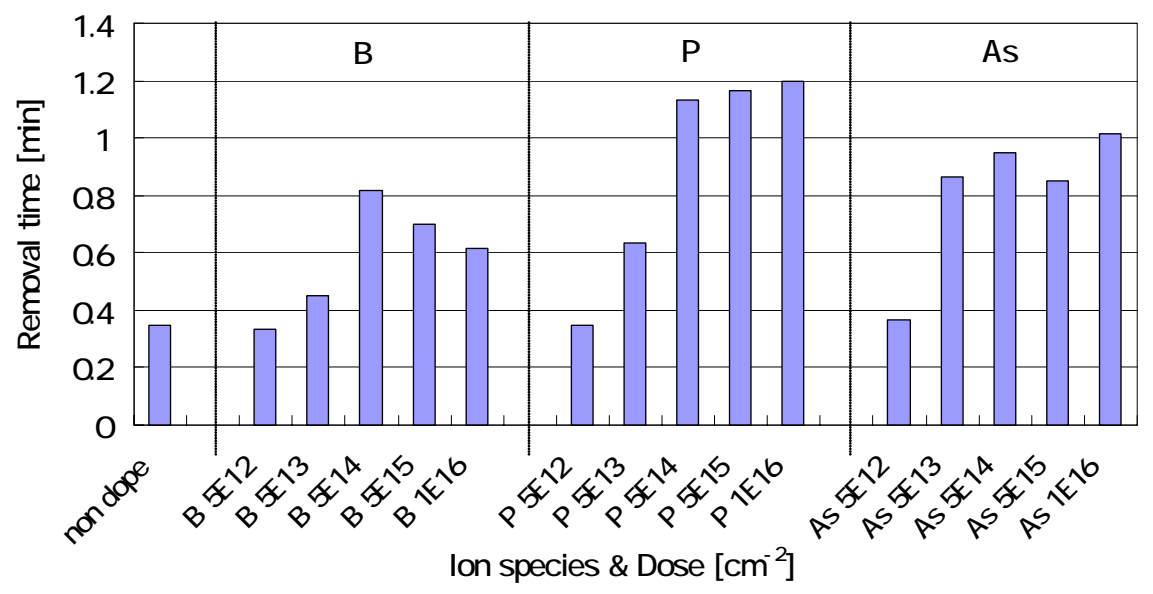

Fig. 10 Removal time when ozone is processed $400^{\circ} \mathrm{C}$ of various ion implantation resists.

becomes long, resembling an exponential curve, when the dose increases, this is not seen on more than $5 \mathrm{e} 13 \mathrm{~cm}^{-2}$ or $5 \mathrm{e} 14 \mathrm{~cm}^{-2}$. For the B implanted sample, the removal time is shortened instead.

The surface of each sample was observed after the temperature rise to $400^{\circ} \mathrm{C}$, and before introducing the ozone gas to investigate this cause.

Figure 11 shows photographs of the area in about a $2 \mathrm{~mm}$ square of each sample. The surface is only slightly blown off, although cracks were generated in the sample by which $5 \mathrm{e} 15 \mathrm{~cm}^{-2}$ or more implanted B. On the other hand, the surface partially
When popping does not occur, the reaction proceeds from the surface. The photoresist of the lower layer is removed after the crust layer: the upper layer.

When popping occurs, on the other hand, the photoresist of the lower layer that does not change in quality and the crust layer, the upper layer, react and are removed at the same time, because the ozone gas flows into the tearing crust layer. Crushing of the crust layer by popping is influenced by physical properties of the respective layers and differences of the layer structure and heating conditions. The 
correlation of the removal time and the amount of the dose (Fig. 10) when popping occurred is thought to be irregularly for this reason.
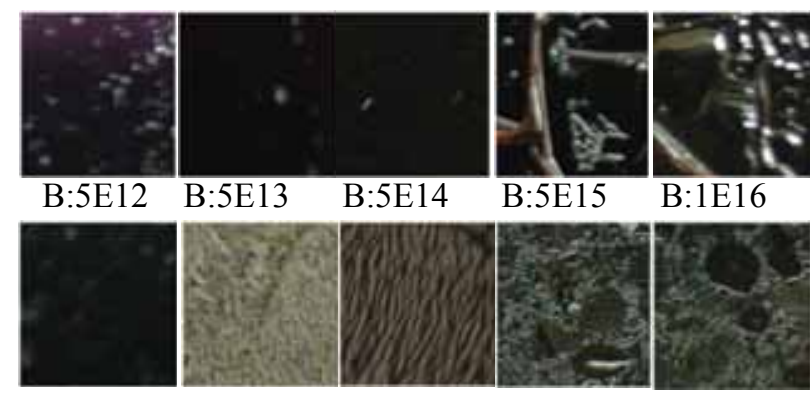

$\mathrm{B}: 1 \mathrm{E} 16$

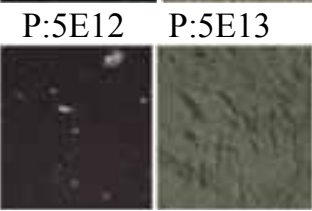

As:5E12 As:5E13
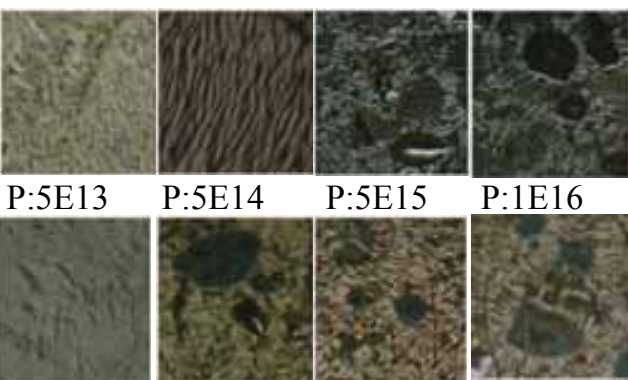

P:1E16
Fig. 11 Photoresist surface at $400^{\circ} \mathrm{C}($ ca. $2 \mathrm{~mm} \times 2 \mathrm{~mm})$.

\section{Conclusion}

The ashing method using ozone gas was examined as a method of removing photoresist using no chemicals or plasma. Highly concentrated (nearly $100 \%$ ) ozone that had not been used for actual production so far was applied. Its removal performance on various photoresists was evaluated. Consequently, the following were found.

1. The reactivity with the ozone gas differs between novolac-resist with the benzene ring structure on the main chain, the $\mathrm{KrF}$-resist with this structure on the side chain and the ArF-resist without this structure. Consequently, the ashing rate of the ArF resist slows more than others on the low-temperature side of about $170^{\circ} \mathrm{C}$ or less; oppositely, it quickened on the high-temperature side.

2. The activation energy of the $\mathrm{KrF}$ resist indicated a value close to that of the novolac resist; the value for the ArF resist was larger than these (Table 1).

3. Irrespective of the ionic species, the photoresist of $1 \mathrm{e} 16 \mathrm{~cm}^{-2}$ dose can be removed with $0.7 \mu \mathrm{m} / \mathrm{min}$ or more in ashing of the ion-implanted photoresist at $400^{\circ} \mathrm{C}$ processing temperature

\section{References}

[1] T. Nishiguchi, et al., "Large-Capacity, High-Purity Ozone Generator for Application to Semiconductor Device Processes", The ECS International Semiconductor Technology Conference (ITSC2001) pp.625-631 (2001).

[2] J. McMurry, "Fundamentals of Organic Chemistry, Fifth Edition”, Tokyo Kagaku Dojin p111.

[3] S. Takechi et al., Alicyclic Polymer for ArF and $\mathrm{KrF}$ Excimer Laser Resist Based on Chemical Amplification. J. Photopolym. Sci. Technol., 5(3) (1992) 439-445.

[4] Y. Kaimoto et al., Alicyclic Polymer for ArF and $\mathrm{KrF}$ Excimer Resist Based on Chemical Amplification. Proc. SPIE, 1672 (1992) 66-73.

[5] M. Horvath, L. Bilitzky and J. Hutener, "Ozone", Elsevier, Amsterdam (1985) p37-39.

[6] K. Koike et al., International Conference on the 20th Anniversary of the Bhopal Gas Tragedy, K-106, December 1-3, 2004.

[7] W. L. Gardner, A. P. Baddorf, and W. M. Holber, J. Vac. Sci. Technol., A15(3) (1997) 1409-1412.

[8] K. Omiya and Y. Kataoka, J. Electrochem. Soc., 145(12) (1998) 4323-4327.

[9] C. K, Huynh and J. C. Mitchener, J. Vac. Sci. Technol., B9(2) (1991) 353-356.

[10] B. Chan, B. Perng, Sheu, L., Y. Chiu, and H. Tao, "Plasma Induced Substrate Damage in High Dose Implant Resist Strip Process," Proc. 8th Int. Symp. on Process- and Plasma-Induced Damage, Corbeil-Essonnes, France, 2003, p. 73. 